\title{
Apolipoprotein E and Alpha Brain Rhythms in Mild Cognitive Impairment: A Multicentric Electroencephalogram Study
}

\author{
Claudio Babiloni, PhD, ${ }^{1,2}$ Luisa Benussi, MD, ${ }^{2}$ Giuliano Binetti, $\mathrm{MD},{ }^{2}$ Emanuele Cassetta, MD, ${ }^{2}$ \\ Gloria Dal Forno, $\mathrm{MD}^{4}$ Claudio Del Percio, PhD, ${ }^{1,2}$ Florinda Ferreri, MD, ${ }^{3,4}$ Raffaele Ferri, MD, ${ }^{5}$ \\ Giovanni Frisoni, MD, ${ }^{2,3}$ Roberta Ghidoni, PhD, ${ }^{2}$ Carlo Miniussi, PhD, ${ }^{2}$ Guido Rodriguez, MD, ${ }^{6}$ \\ Gian Luca Romani, PhD, ${ }^{7,8}$ Rosanna Squitti, $\mathrm{PhD},{ }^{3}$ Maria Carla Ventriglia, $\mathrm{PhD},{ }^{3}$ \\ and Paolo M. Rossini $\mathrm{MD}^{2-4}$
}

\begin{abstract}
Objective: Relationships between the apolipoprotein E $\varepsilon 4$ allele and electroencephalographic (EEG) rhythmicity have been demonstrated in Alzheimer's disease (AD) patients but not in the preclinical stage prodromic to it, namely, mild cognitive impairment (MCI). The present multicentric EEG study tested the hypothesis that presence of $\varepsilon 4$ affects sources of resting EEG rhythms in both MCI and AD subjects. Methods: We enrolled 89 MCI subjects (34.8\% with ع4) and $103 \mathrm{AD}$ patients $(50.4 \%$ with $\varepsilon 4)$. Resting eyes-closed EEG data were recorded for all subjects. EEG rhythms of interest were delta $(2-4 \mathrm{~Hz})$, theta $(4-8 \mathrm{~Hz})$, alpha $1(8-10.5 \mathrm{~Hz})$, alpha $2(10.5-13 \mathrm{~Hz})$, beta $1(13-20 \mathrm{~Hz})$, and beta 2 $(20-30 H z)$. EEG cortical sources were estimated by low-resolution brain electromagnetic tomography. Results: Results showed that amplitude of alpha 1 and 2 sources in occipital, temporal, and limbic areas was lower in subjects carrying the $\varepsilon 4$ allele than in those not carrying the $\varepsilon 4$ allele $(p<0.01)$. This was true for both MCI and AD. For the first time to our knowledge, a relationship was shown between ApoE genotype and global neurophysiological phenotype (ie, cortical alpha rhythmicity) in a preclinical AD condition, MCI, in addition to clinically manifest AD. Interpretation: Such a demonstration motivates future genotype-EEG phenotype studies for the early prediction of AD conversion in individual MCI subjects.
\end{abstract}

Ann Neurol 2006;59:323-334

Mild cognitive impairment (MCI) is characterized by selective memory impairment insufficient to meet criteria for a diagnosis of dementia. ${ }^{1-3}$ This condition is considered as a prodromic stage of Alzheimer's disease (AD),${ }^{4-6}$ because a high rate of progression to $\mathrm{AD}$ has been clearly shown. ${ }^{3,7,8}$ Annual conversion rate to AD is 0.2 to $3.9 \%$ in normal aging (with no MCI symptoms) and 6 to $25 \%$ in MCI subjects. ${ }^{3,9}$ At the end of 6 years of observation, approximately $80 \%$ of $\mathrm{MCI}$ subjects develop $\mathrm{AD} .{ }^{10}$ Taken together, these data suggest the hypothesis that in most (yet not all) of cases, MCI is a transition state on a linear progression toward $\mathrm{AD}$. According to such a hypothesis, early identification of MCI patients might be clinically crucial. ${ }^{11,12}$

In mild $\mathrm{AD}$, electroencephalographic (EEG) rhythms differ from normal elderly (Nold) and vascular dementia subjects, $\mathrm{AD}$ patients being characterized by higher delta $(0-3 \mathrm{~Hz})$ and lower parietooccipital alpha $(8-12 \mathrm{~Hz}) .{ }^{13-17}$ Similarly, MCI subjects have shown increase of theta $(4-7 \mathrm{~Hz})$ power ${ }^{18-20}$ as well as decrease of alpha power, ${ }^{15,18-22}$ when compared with Nold subjects. These EEG parameters have presented an intermediate magnitude in $\mathrm{MCI}$ with respect to Nold and dementia patients. ${ }^{15,23,24}$

Despite the converging evidence of abnormal cortical rhythms in MCI and AD, EEG analysis alone is unable to predict conversion of MCI to dementia. It is reasonable that additional biological parameters are needed for this purpose. In this regard, several studies have shown a strict relationship between apolipopro-
From the ${ }^{1}$ Dipartimento di Fisiologia Umana e Farmacologia, Universitá "La Sapienza" Rome, Italy; ${ }^{2}$ Associazione-IRCCS "San Giovanni di Dio-Futebenefratelli”, Brescia, Italy; ${ }^{3}$ Associazione Dipartimentodi Neuroscience, Ospedele Fatebenefratelli; Isola Tiberina, Rome, Italy; ${ }^{4}$ Clinica Neuroligica Universitá "Campus Biomedico" Rome, Italy; ${ }^{5}$ Department of Neurology, Oasi Institute for Research on Mental Retardation and Brain Aging (IRCCS), Troina, Italy; ${ }^{6}$ Division of Clinical Neurophysiology, University of Genova, Italy; ${ }^{7}$ Dipartimento di Scienze Cliniche e Bioimmagini and ${ }^{8}$ Istitutodi di Tecnologie Avanzate Biiomediche (ITAB), Fondazione "Università Gabriele D’Annunzio," Chieti, Italy.
Received Mar 18, 2005, and in revised form Sep 7. Accepted for publication Sep 8, 2005.

Published December 152005 in Wiley InterScience (www.interscience.wiley.com). DOI: 10.1002/ana.20724

Address correspondence to Dr Babiloni, Dipartimento di Fisiologia Umana e Farmacologia, Università degli Studi di Roma "La Sapienza," P.le Aldo Moro 5, 00185 Rome, Italy.

E-mail: claudio.babiloni@uniroma1.it 
tein $\mathrm{E}(\mathrm{ApoE})$ genotype and late-onset $\mathrm{AD}$. The human ApoE gene has three alleles ( $22, \varepsilon 3, \varepsilon 4), \varepsilon 3$ accounting for the majority of the ApoE gene pool (approximately 70-80\%), whereas $\varepsilon 4$ and $\varepsilon 2$ account for 10 to $15 \%$ and 5 to $10 \%$, respectively. ${ }^{25}$ Previous epidemiological and genetic studies on ApoE have shown that (1) ApoE $\varepsilon 4$ significantly increases the risk of developing $\mathrm{AD}^{25-34}$; (2) ApoE $\varepsilon 2$ and $\mathrm{ApoE} \varepsilon 3$ are associated with a reduced Alzheimer's disease risk ${ }^{32-36}$; (3) association between ApoE $\varepsilon 4$ and $\mathrm{AD}$ risk is stronger in men than in women ${ }^{33,37}$; (4) ApoE $\varepsilon 4$ is the only genetic risk factor associated with $\mathrm{MCI}^{38}$; and (5) ApoE $\varepsilon 4$ predisposes to cognitive decline. ${ }^{39,40}$

ApoE $\varepsilon 4$ is combined with different types of functional brain imaging abnormalities in preclinical as well as in clinically evident cognitive decline of dementia type. ${ }^{41-43}$ Compared with patients with ApoE $\varepsilon 2$ or $\varepsilon 3, A D$ carriers of $\varepsilon 4$ allele had a reduction in neural metabolism and activity both at rest and after activation procedures in temporal, parietal, limbic, and prefrontal areas. ${ }^{44-48}$ Similarly, $\varepsilon 4$ has been found to affect EEG rhythms in $\mathrm{AD} .{ }^{49-52} \mathrm{AD}$ patients with $\varepsilon 4$ had higher theta $(4.1-7.3 \mathrm{~Hz})$ and lower beta $(14.2-$ $20 \mathrm{~Hz}$ ) power than $\mathrm{AD}$ patients with $\varepsilon 2$ or $\varepsilon 3 .^{51}$ Furthermore, compared with $\mathrm{AD}$ patients with $\varepsilon 2$ or $\varepsilon 3$, $\mathrm{AD}$ patients with $\varepsilon 4$ showed: (1) higher theta and lower beta power at baseline recording ${ }^{52}$; and (2) higher delta $(1.5-3.9 \mathrm{~Hz})$ and lower alpha $(7.6-13.9 \mathrm{~Hz})$ power at the follow-up (3 years later). ${ }^{52}$ Finally, ApoE $\varepsilon 4$ has been associated with selective decrement of corticocortical functional connectivity in $\mathrm{AD}$, as shown by a reduction of right and left temporoparietal, right temporofrontal, and left occipitoparietal EEG coherence at the alpha band $(8-13 \mathrm{~Hz}){ }^{49}$

To our knowledge, the ApoE $\varepsilon 4$ effects on EEG rhythmicity in the preclinical stage of $\mathrm{AD}$, namely MCI, have not been previously investigated. The present EEG study tested the hypothesis that the ApoE $\varepsilon 4$ allele affects cortical sources of resting EEG rhythms in MCI.

\section{Materials and Methods}

Part of the procedures (EEG recordings and low-resolution brain electromagnetic tomography [LORETA] analysis) pertinent to this study as well as a description of the potential meaning of cortical rhythms in aging have been extensively described in two recent papers. ${ }^{17,53}$ However, it should be stressed that the aims of the previous and current studies are totally different. The previous studies aimed at analyzing (1) the distributed EEG sources specific to mild $\mathrm{AD}$ as compared with vascular dementia $(\mathrm{VaD})$ or normal aging ${ }^{17}$ and (2) the distributed EEG sources across physiological aging. ${ }^{53}$ In contrast, this study focused on the effects of the ApoE $\varepsilon 4$ allele on EEG rhythmicity in the MCI subjects. We apologize for some repetitions in the description of the present procedures with respect to those reported in the previous articles using similar EEG methodological approach. This was done to stress the fact that already validated methodological procedures were used.

\section{Subjects}

Patients population included 89 MCI subjects and 103 AD patients, whereas the control group included 86 cognitively Nold individuals. Local institutional ethics committees approved the study. All experiments were performed with the informed and overt consent of each participant or caregiver, in line with the Code of Ethics of the World Medical Association (Declaration of Helsinki) and the standards established by the authors' institutional review board.

\section{Diagnostic Criteria}

Probable $\mathrm{AD}$ was diagnosed according to National Institute of Neurological and Communication Disorders Alzheimer's Disease and Related Disorders Association ${ }^{54}$ and Diagnostic Statistical Manual IV criteria. All recruited AD patients underwent general medical, neurological, and psychiatric assessments. Patients were also rated with several standardized screening, diagnostic, and severity instruments that included Mini-Mental State Examination (MMSE), ${ }^{55}$ Clinical Dementia Rating Scale (CDR), ${ }^{56}$ Geriatric Depression Scale (GDS), ${ }^{57}$ Hachinski Ischemic Scale (HIS), ${ }^{58}$ and the Instrumental Activities of Daily Living scale (IADL). ${ }^{59}$ Neuroimaging diagnostic procedures (computed tomography or magnetic resonance imaging) and complete blood chemistries tests were conducted to exclude other causes of progressive or reversible dementias, to have a homogenous $\mathrm{AD}$ patient sample. Exclusion criteria included the presence of symptoms suggestive of (1) frontotemporal dementia, (2) vascular dementia, (3) extrapyramidal syndromes, (4) reversible dementias, (5) fluctuations in cognitive performance as well as of movement disorders and visual hallucinations suggestive of a possible Lewy body dementia. Of note, antidepressant and/or antihypertensive were suspended for 24 to 48 hours before EEG recordings.

Inclusion and exclusion criteria for MCI diagnosis aimed at selecting elderly persons with objective cognitive deficits, especially in the memory domain, who did not meet criteria for dementia or $\mathrm{AD} .{ }^{1,3,60-64}$ Inclusion criteria for MCI were represented by (1) objective memory impairment on neuropsychological evaluation, as defined by performances 1.5 or higher standard deviation below age and education-matched controls; (2) full autonomy in the activities of daily living as documented by dedicated tests and by history and evidence of independent living; and (3) a CDR of 0.5. Exclusion criteria for $\mathrm{MCI}$ were (1) $\mathrm{AD}$, as diagnosed by the procedures described above; (2) evidence of concomitant dementia such as frontotemporal, vascular dementia, reversible dementias, fluctuations in cognitive performance, and/or features of mixed dementias; (3) evidence of concomitant extrapyramidal symptoms; (4) clinical and indirect evidence of depression as shown by GDS scores greater than 14; (5) other psychiatric diseases, epilepsy, drug addiction, alcohol dependence, and use of psychoactive drugs or drugs interfering with brain cognitive functions including acetylcholinesterase inhibitors; and (6) current or previous systemic diseases (including diabetes mellitus) or traumatic brain injuries. Subjects' blood examination for the evaluation of ApoE was per- 
Table 1. Demographic and Neuropsychological Data of Participants

\begin{tabular}{lccr}
\hline Characteristic & Nold & MCI & AD \\
\hline $\mathrm{N}$ & 86 & 89 & 103 \\
Age (yr) & $70.1( \pm 0.6 \mathrm{SE})$ & $70.8( \pm 0.9 \mathrm{SE})$ & $75.1( \pm 0.8 \mathrm{SE})$ \\
Sex (F/M) & $53 / 33$ & $53 / 36$ & $84 / 19$ \\
MMSE & $28.1( \pm 0.1 \mathrm{SE})$ & $25.7( \pm 0.3 \mathrm{SE})$ & $20.6( \pm 0.3 \mathrm{SE})$ \\
Education (yr) & $9.6( \pm 0.4 \mathrm{SE})$ & $7.6( \pm 0.4 \mathrm{SE})$ & $6.3( \pm 0.4 \mathrm{SE})$ \\
\hline
\end{tabular}

Nold = normal elderly; $\mathrm{MCI}=$ mild cognitive impairment; $\mathrm{AD}=$ Alzheimer's disease; $\mathrm{SE}=$ standard error; MMSE $=$ Mini-Mental State Examination.

formed on MCI subjects as well. On the basis of such genotyping, the $\mathrm{AD}$ group was subdivided in two genetic subgroups: $\mathrm{AD}$ carriers of the ApoE $\varepsilon 4$ allele (52 subjects) and $\mathrm{AD}$ noncarriers of the ApoE $\varepsilon 4$ allele (51 subjects). As the $\mathrm{AD}$ group, the MCI group was subdivided in two genetic subgroups: MCI carriers of the ApoE $\varepsilon 4$ allele (31 subjects) and MCI noncarriers of the ApoE $\varepsilon 4$ allele (58 subjects). Besides such differences in ApoE genotyping, these subgroups did not significantly differ in demographic or in clinical parameters.

To preliminarily ascertain that the selected $\mathrm{AD}$ patients and MCI subjects indeed presented the pattern of EEG rhythmic activity that typically is combined with the disease and cognitive impairment, we also recruited a control group of healthy elderly subjects (Nold), mostly among nonconsanguineous patients' relatives. All Nold subjects underwent physical and neurological examinations as well as cognitive screening. Subjects affected by chronic systemic illnesses, subjects receiving psychoactive drugs, and subjects with a history of present or previous neurological or psychiatric disease were excluded. All Nold subjects had a GDS score less than 14.

Table 1 summarizes the relevant demographic and clinical data of participants. As expected, women were overrepresented in the $\mathrm{AD}$ group. Because there is no previous evidence of sex-specific effects on EEG rhythms, it was felt that this would not interfere with the results. Table 2 reports the relevant demographic and clinical parameters of participants subdivided in two genetic subgroups: ApoE $\varepsilon 4$ allele $\mathrm{MCI} / \mathrm{AD}$ carriers and noncarriers, respectively. Age and education were used as covariates in the statistical evaluation of the cortical sources of EEG rhythms, to remove possible confounding effects.

\section{Apolipoprotein E Genotyping}

Genomic DNA was extracted from whole-blood samples of $\mathrm{AD}$ patients and MCI subjects. ApoE genotype was determined using standard methods. ${ }^{65}$

\section{Electroencephalogram Recordings}

EEG was recorded in waking-rest conditions (eyes-closed, $0.3-70 \mathrm{~Hz}$ bandpass) from 19 scalp electrodes positioned according to the International 10-20 System (ie, Fp1, Fp2, F7, F3, Fz, F4, F8, T3, C3, Cz, C4, T4, T5, P3, Pz, P4, T6, O1, O2). A specific reference electrode was not imposed, because preliminary data analysis and LORETA source analysis were conducted after EEG data were re-referenced to a common average reference. To monitor eye movements, we also collected the electrooculogram $(0.3-70 \mathrm{~Hz}$ bandpass). All data were digitized in continuous recording mode $(128-256 \mathrm{~Hz}$ sampling rate). In all subjects, EEG recordings were performed at about lunch time. State of vigilance was controlled by on-line visual inspection of EEG traces during recording session and subjects' drowsiness was avoided by verbal warnings. No patient received medications that could influence EEG rhythms such as antidepressant or benzodiazepines. Of note, EEG recordings lasting 5 minutes allowed the comparison of the results with several previous $\mathrm{AD}$ studies using either EEG recording periods shorter than 5 minutes $^{17,66-71}$ or shorter than 1 minute. ${ }^{13,14}$ Longer resting EEG recordings in $\mathrm{AD}$ patients would have reduced data variability but would have increased the possibility of EEG rhythmic oscillations slowing because of reduced vigilance and arousal.

EEG data were analyzed and fragmented off-line in consecutive epochs of 2 seconds. For standardization purposes, preliminary data analysis was centralized in one research unit. The EEG epochs with ocular, muscular, and other types of artifact were preliminary identified by a computerized automatic procedure. EEG epochs with ocular artifacts $(<15 \%$ of the total) were corrected by an autoregressive method. ${ }^{72}$ Two independent experimenters manually confirmed the EEG segments accepted for further analysis.

\section{Spectral Analysis of the Electroencephalogram Data}

A digital Fast Fourier Transform (FFT)-based power spectrum analysis (Welch technique, Hanning windowing function, no phase shift) was conducted by computing power density of EEG rhythms with $0.5 \mathrm{~Hz}$ frequency resolution. The following frequency bands were studied: delta $(2-4 \mathrm{~Hz})$, theta $(4-8 \mathrm{~Hz})$, alpha $1(8-10.5 \mathrm{~Hz})$, alpha $2(10.5-13 \mathrm{~Hz})$, beta $1(13-20 \mathrm{~Hz})$, and beta $2(20-30 \mathrm{~Hz})$ in line with previous EEG studies on dementia ${ }^{17,19,71-77}$ Of note, sharing of a frequency bin by two contiguous bands is a widely accepted procedure. ${ }^{19,73,-91}$

Choice of fixed EEG bands did not account for individual alpha frequency (IAF) peak, defined as the frequency associated with the strongest EEG power at the extended alpha range. This choice should not affect the results, because most of the subjects had IAF peaks within the alpha 1 band (8$10.5 \mathrm{~Hz})$. In particular, mean IAF peak was $9.3 \mathrm{~Hz}( \pm 0.1$ standard error [SE]) in Nold subjects, $8.9 \mathrm{~Hz}( \pm 0.1 \mathrm{SE})$ in MCI subjects, and $8.3 \mathrm{~Hz}( \pm 0.1 \mathrm{SE})$ in $\mathrm{AD}$ patients. In the two MCI subgroups, the mean IAF peak was $9.2 \mathrm{~Hz}( \pm 0.2$ $\mathrm{SE})$ in MCI subjects not carrying the $\varepsilon 4$ allele (MCI-) and $8.6 \mathrm{~Hz}( \pm 0.2 \mathrm{SE})$ in MCI carriers of the $\varepsilon 4$ allele $(\mathrm{MCI}+)$. 
Table 2. Demographic and Neuropsychological Data of the MCI and AD Subjects, Each Clustered in Two Genetic Subgroups: $M C I / A D$ Not Carrying ApoE $\varepsilon 4$ allele (ApoE $\varepsilon 4$ noncarriers) and MCI/AD carrying the $\varepsilon 4$ allele (ApoE $\varepsilon 4$ carriers)

\begin{tabular}{|c|c|c|c|c|}
\hline \multirow[b]{2}{*}{ Characteristic } & \multicolumn{2}{|c|}{ MCI } & \multicolumn{2}{|c|}{$\mathrm{AD}$} \\
\hline & ApoE $\varepsilon 4$ Noncarriers & ApoE $\varepsilon 4$ Carriers & ApoE $\varepsilon 4$ Noncarriers & ApoE $\varepsilon 4$ Carriers \\
\hline $\mathrm{N}$ & 58 & 31 & 51 & 52 \\
\hline Age $(y r)$ & 70.9 ( $\pm 1.2 \mathrm{SE})$ & 70.7 ( $\pm 1.2 \mathrm{SE})$ & 74.9 ( $\pm 1.3 \mathrm{SE})$ & $75.2( \pm 1.2 \mathrm{SE})$ \\
\hline $\operatorname{Sex}(F / M)$ & $35 / 23$ & $18 / 13$ & $44 / 7$ & $40 / 12$ \\
\hline MMSE & $25.8( \pm 0.3 \mathrm{SE})$ & $25.4( \pm 0.4 \mathrm{SE})$ & $21.2( \pm 0.4 \mathrm{SE})$ & $20( \pm 0.5 \mathrm{SE})$ \\
\hline Education (yr) & $7.3( \pm 0.5 \mathrm{SE})$ & $8( \pm 0.8 \mathrm{SE})$ & $6.7( \pm 0.2 \mathrm{SE})$ & $5.8( \pm 0.4 \mathrm{SE})$ \\
\hline
\end{tabular}

$\mathrm{MCI}=$ mild cognitive impairment; $\mathrm{AD}=$ Alzheimer's disease; $\mathrm{ApoE}=$ apolipoprotein $\mathrm{E} ; \mathrm{SE}=$ standard error; MMSE $=$ Mini-Mental State Examination.

In the two $\mathrm{AD}$ subgroups, the mean IAF peak was $8.4 \mathrm{~Hz}$ $( \pm 0.2$ standard error, SE) in $\mathrm{AD}-$ and $8.2 \mathrm{~Hz}( \pm 0.2 \mathrm{SE})$ in $\mathrm{AD}+$. To control the effect of IAF on the EEG comparisons between these two subgroups, we used IAF peak as a covariate (together with age and education) for further statistics.

\section{Cortical Source Analysis of the}

Electroencephalographic Rhythms by Low-Resolution

Brain Electromagnetic Tomography

LORETA technique was used for EEG source analysis, ${ }^{14,17,92-96}$ because its validity was tested with invasive depth EEG recordings, ${ }^{97}$ positron emission tomography, ${ }^{98}$ and simultaneous functional magnetic resonance imaging scans. ${ }^{99,100}$ LORETA computes three-dimensional linear solutions (LORETA solutions) for EEG inverse problem within a three-shell spherical head model including scalp, skull, and brain compartments. Brain compartment is restricted to the cortical gray matter/hippocampus of a head model coregistered to Talairach probability brain atlas and digitized at the Brain Imaging Center of the Montreal Neurologic Institute. ${ }^{101}$ This compartment includes 2,394 voxels ( $7 \mathrm{~mm}$ resolution), each voxel containing an equivalent current dipole.

LORETA source analysis is reference-free, in that one obtains the same LORETA source distribution for EEG data referenced to any reference electrode including common average. Furthermore, LORETA can be used from data collected by low spatial sampling of the 10-20 system (19 electrodes) when cortical sources are estimated from resting EEG rhythms. Several previous studies have shown that these rhythms are generated by largely distributed cortical sources that can be accurately investigated by standard 10-20 system and LORETA. ${ }^{17,102-112}$

LORETA solutions consisted of voxel current density values able to predict EEG spectral power density at scalp electrodes. The LORETA data for each subject were normalized to unit global power (over all discrete frequencies and voxels), to reduce variance and thus enhance tomographic results. The general procedure fitted the LORETA solutions in a Gaussian distribution and reduced intersubject variability. ${ }^{73,113}$ Of note, other methods of normalization using the principal component analysis are effective for estimating the subjective global factor scale of the EEG data. ${ }^{114}$ These methods are not yet available in the LORETA package, so they were not used here.
Solutions of the EEG inverse problem are underdetermined and ill-conditioned when the number of spatial samples (electrodes) is lower than that of the unknown samples (current density at each voxel). To account for that, the cortical LORETA solutions predicting scalp EEG spectral power density were regularized to estimate distributed rather than discrete EEG source patterns. ${ }^{92-94}$ Such spatial smoothing of the LORETA solutions (resolution in centimeters) can reliably take into account the slight change in the cortical volume (resolution in millimeters) present in $\mathrm{AD}$ subjects. In line with the low spatial resolution of the LORETA technique, we collapsed LORETA solutions at frontal, central, temporal, parietal, occipital, and limbic regions of the brain model coded into Talairach space. The Brodmann areas listed in Table 3 formed each of these regions of interest (ROIs).

\section{Statistical Analysis of the Low-Resolution Brain Electromagnetic Tomography Solutions}

Regional normalized LORETA solutions were used by analysis of variance (ANOVA) analysis, using subjects' age and education as covariates. Mauchly's test evaluated the sphericity assumption. Correction of the degrees of freedom was made with the Greenhouse-Geisser procedure. Duncan test was used for post hoc comparisons $(p<0.05)$. In particular, two ANOVA designs were addressed in this study. (1) A first control ANOVA analysis verified the sensitivity of the present methodological approach, namely, to estimate EEG source differences among Nold, MCI, and AD groups. This ANOVA analysis used Group (Nold, MCI, AD), Band (delta, theta, alpha 1 , alpha 2 , beta 1 , beta 2 ), and ROI (central, frontal, parietal, occipital, temporal, limbic). The LORETA solutions of interest were those showing progressive changes in mean magnitude across Nold, MCI, and AD subjects (Nold $\rightarrow \mathrm{MCI} \rightarrow \mathrm{AD}$ and Nold $\leftarrow \mathrm{MCI} \leftarrow \mathrm{AD}$ ). Furthermore, these solutions had to show linear correlations with MMSE score in all subjects as a single group (Bonferroni-corrected Pearson test, $p<0.05$ ). (2) The second ANOVA evaluated the working hypothesis, namely, the existence of EEG source differences between $\mathrm{MCI}+$ and $\mathrm{AD}+$ versus $\mathrm{MCI}-$ and $\mathrm{AD}-$ groups. This ANOVA design used Group (MCI, AD), Genotype (presence or absence of $\varepsilon 4$ ), Band (delta, theta, alpha 1, alpha 2, beta 1, beta 2), and ROI (central, frontal, parietal, occipital, temporal, limbic) as factors. The planned Duncan post hoc testing evaluated the 
Table 3. LORETA Brodmann Areas into the Regions of Interest

\begin{tabular}{ll}
\hline Region & \multicolumn{1}{c}{ Area } \\
\hline Frontal & $8,9,10,11,44,45,46,47$ \\
Central & $1,2,3,4,6$ \\
Parietal & $5,7,30,39,40,43$ \\
Temporal & $20,21,22,37,38,41,42$ \\
Occipital & $17,18,19$ \\
Limbic & $31,32,33,34,35,36$ \\
\hline
\end{tabular}

LORETA solutions were collapsed in frontal, central, parietal, temporal, occipital, and limbic ROIs.

LORETA $=$ low-resolution brain electromagnetic tomography.

prediction of the working hypothesis. That prediction would be confirmed by the following LORETA patterns: $\Delta 4$ noncarriers $\neq \varepsilon 4$ carriers in both MCI and AD groups.

\section{Results}

Control Analysis

Grand average of LORETA solutions (ie, relative current density at cortical voxels) modeling the distributed EEG sources for delta, theta, alpha 1, alpha 2, beta 1, and beta 2 bands presented specific spatial features in Nold, MCI, and AD groups. Compared with the Nold group, $\mathrm{AD}$ patients showed an increase of widespread delta sources, along with a drastic reduction of parietooccipital alpha 1 sources. With respect to the Nold and $\mathrm{AD}$ groups, $\mathrm{MCI}$ subjects showed intermediate magnitude of alpha 1 sources and greater magnitude of alpha 2 sources.

These data were used for an ANOVA control analysis to test the hypothesis that MCI and $\mathrm{AD}$ subjects had typical EEG features as described by the literature. LORETA solutions (distributed EEG sources) showed a statistical ANOVA interaction $(\mathrm{F}[50,6975]=2.6$; MSe $=0.6 ; p<0.00001)$ among the factors Group (Nold, MCI, AD), Band (delta, theta, alpha 1, alpha 2, beta 1 , beta 2), and ROI (central, frontal, parietal, occipital, temporal, limbic). It was shown that parietal, occipital, temporal, and limbic alpha 1 sources had stronger amplitudes in Nold versus MCI $(p<$ $0.00001)$ and in $\mathrm{MCI}$ versus $\mathrm{AD}(p<0.01)$. Furthermore, the amplitude of the parietal delta source was stronger in $\mathrm{AD}$ than Nold $(p<0.005)$. Finally, parietal alpha 2 sources showed stronger amplitude in MCI than Nold $(p<0.0001)$ and AD $(p<0.0001)$. MMSE score correlated positively with parietal $(r=$ $0.21, p=0.0003$; Bonferroni threshold to $p<$ $0.0125)$, occipital $(r=0.24, p=0.00004)$, temporal $(r=0.21, p=0.0003)$, and limbic $(r=0.23, p=$ $0.00006)$ alpha 1 source intensities. These results demonstrated the existence of significant EEG source intensity differences among Nold, MCI, and AD groups.
Topography of the Electroencephalographic Cortical Sources Estimated by Low-Resolution Brain Electromagnetic Tomography in Apolipoprotein E $\varepsilon 4$ Carriers and Noncarriers

For illustrative purposes, Figure 1 maps the grand average of the LORETA solutions (ie, relative current density at cortical voxels) modeling the distributed EEG sources for delta, theta, alpha 1, alpha 2, beta 1, and beta 2 bands in $\mathrm{MCI}$ and $\mathrm{AD}$ subjects not carrying the $\varepsilon 4$ allele $(\mathrm{MCI}-, \mathrm{AD}-)$ and in $\mathrm{MCI}$ and $\mathrm{AD}$ carriers of the $\varepsilon 4$ allele $(\mathrm{MCI}+, \mathrm{AD}+)$. Both $\mathrm{MCI}-$ and $\mathrm{AD}$ - groups presented alpha 1 sources with maximal values of the relative current density distributed in the parietooccipital regions. Delta, theta and alpha 2 sources had moderate relative current density values when compared with alpha 1 sources. Finally, beta 1 and beta 2 sources were characterized by the lowest relative current density values. In comparison, $\mathrm{MCI}+$ and $\mathrm{AD}+\varepsilon 4$ carriers showed a reduction of alpha 1 and alpha 2 sources intensities.

\section{Statistical Analysis of the Electroencephalographic Cortical Sources Estimated by Low-Resolution Brain Electromagnetic Tomography Characterizing Apolipoprotein E $\varepsilon 4$ Noncarriers with respect to the ApoE $\varepsilon 4$ Carriers}

ANOVA analysis for the evaluation of the working hypothesis showed a statistical interaction $(\mathrm{F}[25,4,700]=$ 2.8; MSe $=0.5 ; p<0.004)$ among the factors Genotype (presence or absence of ApoE $\varepsilon 4$ allele), Band (delta, theta, alpha 1 , alpha 2, beta 1 , beta 2 ), and ROI (central, frontal, parietal, occipital, temporal, limbic). Figure 2 shows the mean regional LORETA solutions relative to this statistical ANOVA interaction. In line with the working hypothesis, alpha 1 and alpha 2 sources in occipital, temporal, and limbic areas showed stronger amplitude in noncarriers compared to carriers of the ApoE $\varepsilon 4(p<0.01)$. This was true for both $\mathrm{MCI}$ and $\mathrm{AD}$ subjects, because there was no interaction with the factor Genotype (presence or absence of the $\varepsilon 4$ allele). As a statistical trend, temporal theta source showed stronger amplitude in carriers compared with noncarriers of the ApoE $\varepsilon 4(p<0.07)$.

The ANOVA analysis also showed a statistical interaction among the factors Group (MCI, AD), Band (delta, theta, alpha 1, alpha 2, beta 1, beta 2), and ROI (central, frontal, parietal, occipital, temporal, limbic). Figure 3 shows mean regional LORETA solutions relative to this statistical ANOVA interaction. Alpha 1 (central, parietal, occipital, temporal and limbic areas) and alpha 2 (parietal and occipital areas) sources were stronger in MCI than $\mathrm{AD}(p<0.03)$. Furthermore, delta (occipital and limbic areas) and theta (occipital areas) sources were stronger in $\mathrm{AD}$ compared with MCI $(p<0.03)$. 


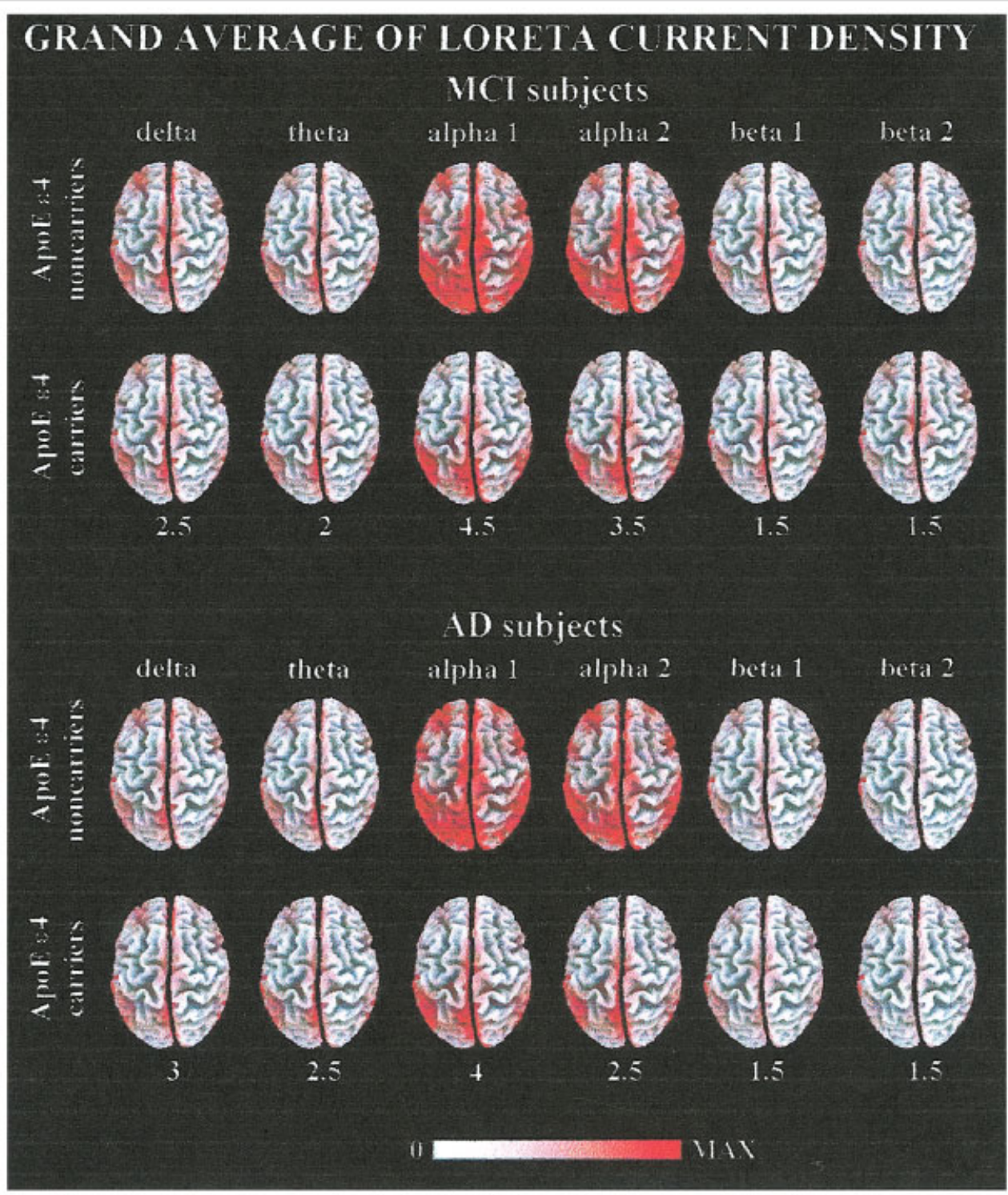

Fig 1. Grand average of low-resolution brain electromagnetic tomography (LORETA) solutions (ie, normalized relative current density at the cortical voxels) modeling the distributed EEG sources for delta (2-4Hz), theta (4-8Hz), alpha 1 (8-10.5Hz), alpha 2 $(10.5-13 \mathrm{~Hz})$, beta $1(13-20 \mathrm{~Hz})$, and beta $2(20-30 \mathrm{~Hz})$ bands in mild cognitive impairment (MCI) and Alzheimer's disease (AD) groups, both subdivided in two genetic subgroups: MCI-/AD- not carrying the apolipoprotein E (ApoE) $\varepsilon 4$ and MCI+I $A D+$ carrying the $\varepsilon 4$ allele. The left side of the maps (top view) corresponds to the left hemisphere. Color scale: all power estimates were scaled based on the averaged maximum value (ie, alpha 1 power value of occipital region in MCI not carrying the ApoE $\varepsilon 4$ allele). The maximal power value is reported under each column.

\section{Discussion}

Electroencephalographic Characteristics in Mild Cognitive Impairment and Alzheimer's Disease Subjects with ApoE $\varepsilon 4$

Alpha sources in occipital, temporal, and limbic areas showed lower amplitude in MCI and AD subjects with ApoE $\varepsilon 4$ compared with those not carrying $\varepsilon 4$ $(p<0.01)$. Furthermore, temporal theta source showed a trend for stronger amplitude in ApoE $\varepsilon 4$ carriers compared with noncarriers $(p<0.07)$. These results extend in the cortical spatial domain previous scalp EEG evidence in AD carrying $\varepsilon 4 .{ }^{49-52}$ They complement previous evidence of reduced regional cerebral blood flow and/or glucose metabolism in temporal, parietal, limbic, and prefrontal areas of $\mathrm{AD}$ carrying 84 when compared with $\mathrm{AD}$ noncarriers. ${ }^{44-48}$ As a novelty, they demonstrate a similar trend for the preclinical stage of AD, namely, MCI. These results warrant further EEG investigations in normal subjects who carry the $\varepsilon 4$ allele. Indeed, previous evidence has 


\section{STATISTICAL ANOVA INTERACTION BETWEEN GENOTYPE, BAND AND ROI}

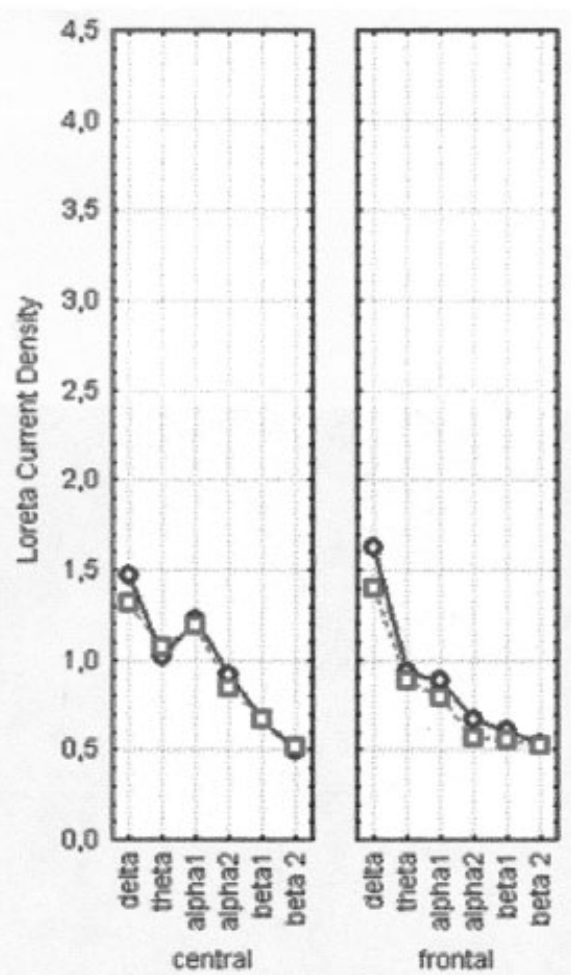

- - ApoE $\approx 4$ noncarriers

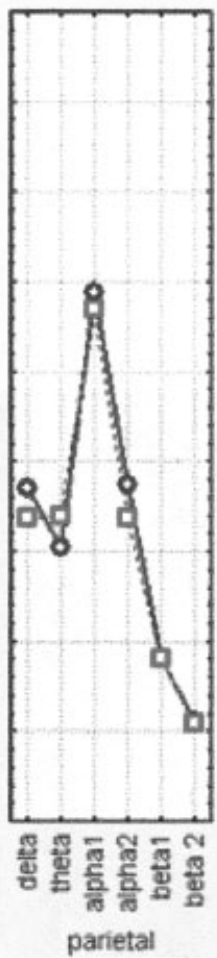

ApoE 84 carriers
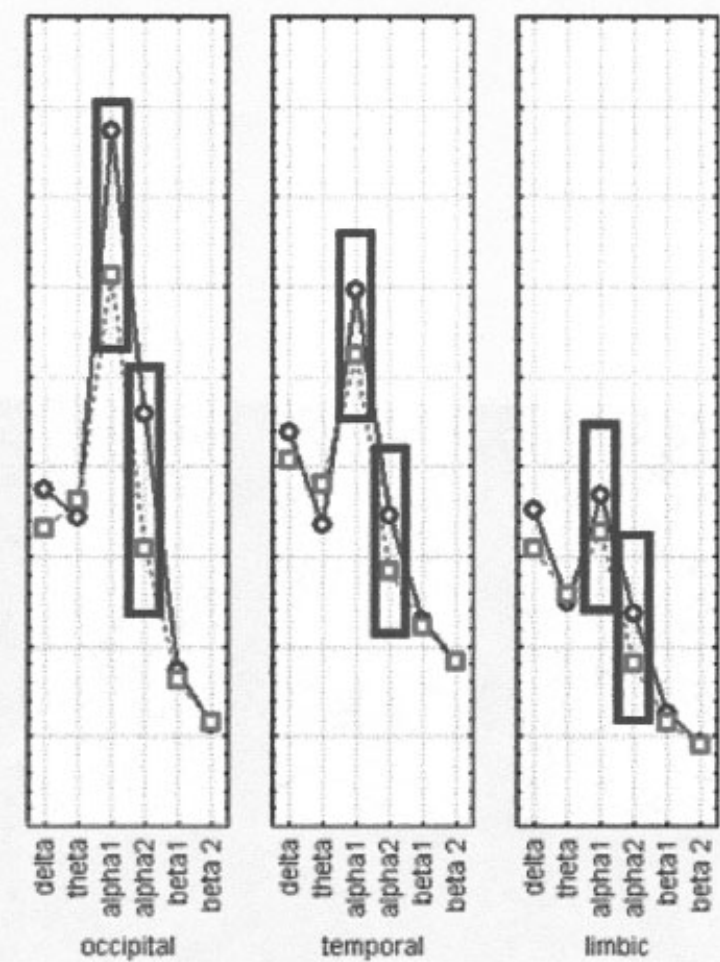

ApoE 84 noncarriers $>$ ApoE 84 carriers (p<0.05)

Fig 2. Regional low-resolution brain electromagnetic tomography (LORETA) solutions (mean across subjects) relative to a statistical analysis of variance (ANOVA) interaction among the factors Genotype (presence or absence of the ApoE $\varepsilon 4$ allele), Band (delta, theta, alpha 1, alpha 2, beta 1, beta 2), and region of interest (ROI; central, frontal, parietal, occipital, temporal, limbic). This ANOVA design used the normalized relative current density values at ROI level as a dependent variable. Subjects' age, education, and individual alpha frequency peak (IAF) were used as covariates. Regional LORETA solutions modeled the electroencephalographic (EEG) relative power spectra as shown by a sort of "virtual" intracranial macroelectrodes located on the macrocortical regions of interest. (rectangles) Cortical regions and frequency bands in which LORETA solutions presented statistically significant different values between subjects plus or minus for the apolipoprotein $E$ (ApoE) $\varepsilon 4$ allele $(\mathrm{p}<0.05$, planned Duncan post hoc testing). See Materials and Methods for further details.

shown a reduction of resting posterior cortical activity in cognitively intact individuals with ApoE $\varepsilon 4$ allele compared with subjects not carrying ApoE $\varepsilon 4$ allele. ${ }^{41,42}$

The open question of this study is why alpha sources were lower in amplitude in $\mathrm{MCI}$ and $\mathrm{AD} \varepsilon 4$ carriers. We do not have a conclusive explanation at this early stage of research. As introductory basic aspects, it is well known that brain of an individual with $\mathrm{AD}$ exhibits extracellular plaques of aggregated $\beta$-amyloid protein (Abeta) and intracellular neurofibrillary tangles that contain hyperphosphorylated tau protein. In brain, degradation and clearance of Abeta would imply insulin-degrading enzyme, which is reduced by approximately $50 \%$ at hippocampus of $\varepsilon 4+\mathrm{AD}$ patients compared with $\varepsilon 4$ - patients and controls. ${ }^{15}$ Furthermore, $\mathrm{AD}$ is characterized by a profound loss of basal forebrain cholinergic neurons that innervate hippocampus and neocortex. ${ }^{116}$ Finally, alpha rhythms are mainly modulated by thalamocortical and corticocortical interactions. ${ }^{117-119}$ Within extended alpha band $(8-13 \mathrm{~Hz})$, low-band alpha would be mainly related to subject's global attentional readiness, whereas highband alpha would reflect the engagement of specific neural channels for the elaboration of sensorimotor or semantic information. ${ }^{80,85,86}$ At rest, the voltage of the alpha rhythms would be inversely correlated with the cortical excitability and level of attention processes depending on the novelty and importance of the stimulus. $^{80,85,86,117,120,121}$ For this reason, it has been suggested that the amplitude of alpha rhythms and corresponding cortical excitability reflect at least in part the time-varying inputs of forebrain cholinergic pathways. ${ }^{122}$ 


\section{STATISTICAL ANOVA INTERACTION BETWEEN GROUP, BAND AND ROI}
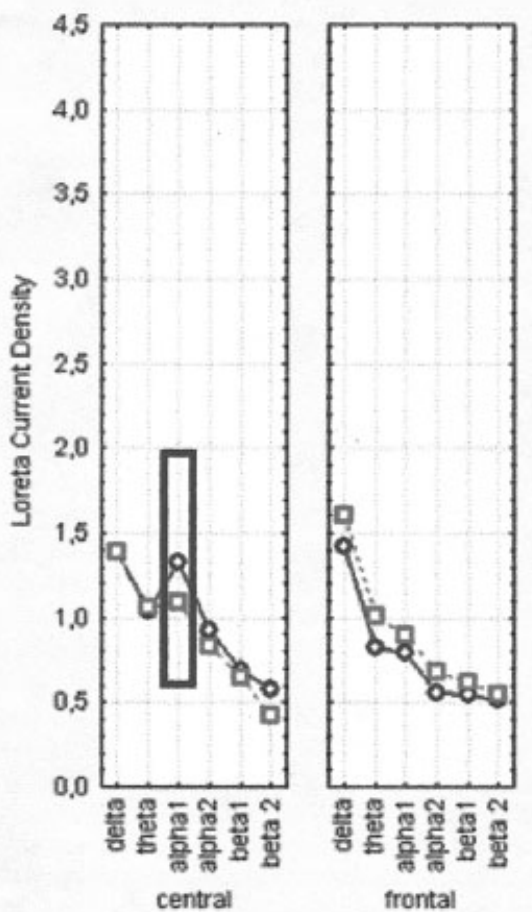

$\longrightarrow$ MCI
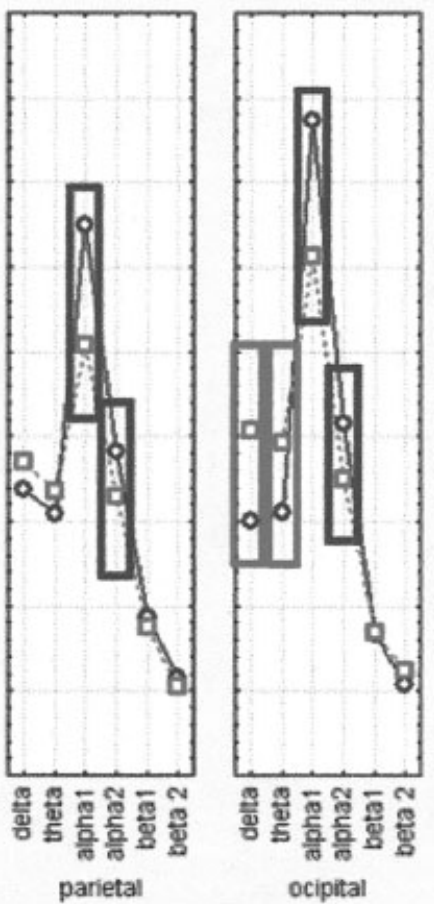

$\mathrm{MCI}>\mathrm{AD}(\mathrm{p}<0.05)$

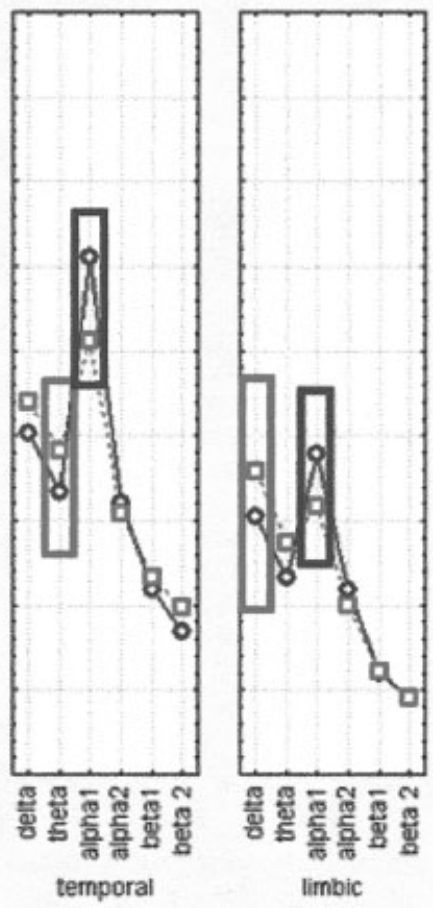

$\mathrm{MCI}<\mathrm{AD}(\mathrm{p}<0.05)$

Fig 3. Regional low-resolution brain electromagnetic tomography (LORETA) solutions (mean across subjects) relative to a statistical analysis of variance (ANOVA) interaction among the factors Group (mild cognitive impairment [MCI], Alzheimer's disease [AD]), Band (delta, theta, alpha 1, alpha 2, beta 1, beta 2), and ROI (central, frontal, parietal, occipital, temporal, limbic). This ANOVA design used the normalized relative current density values at ROI level as a dependent variable. Subjects' age, education, and individual alpha frequency peak (IAF) were used as covariates. The rectangles indicate the cortical regions and frequency bands in which LORETA solutions presented statistically significant different values between MCI and AD groups (p $<0.05$, planned Duncan post hoc testing). See Materials and Methods for further details.

Keeping in mind these data, it could be speculated that, in MCI and $\mathrm{AD} \varepsilon 4$ carriers, reduced degradation and clearance of Abeta would result in a great impairment of the cholinergic basal forebrain, hippocampal, and thalamocortical networks. As a consequence, there would be an increase of the excitatory activity of the cholinergic brainstem pathway, ${ }^{123-125}$ which would desynchronize resting posterior alpha rhythms ${ }^{126}$ and might enhance cortical excitability in $\mathrm{AD}$ patients. ${ }^{127-132}$ Previous studies have indeed shown that resting EEG rhythms, including alpha, are lowered by experimental or clinical impairment of the cholinergic basal forebrain. ${ }^{13-15,17,76,77,133-135}$ In contrast, brainstem cholinergic innervations of the thalamus are relatively spared in $\mathrm{AD}$ patients. ${ }^{134-139}$

\section{Conclusions}

The present EEG study evaluated cortical rhythms in $\mathrm{MCI}$ and $\mathrm{AD}$ subjects carrying or not a factor risk of dementia such as ApoE $\varepsilon 4$ allele. Amplitude of alpha sources in occipital, temporal, and limbic areas was lower in subjects carrying the ApoE $\varepsilon 4$ than noncarrier individuals $(p<0.01)$. This was true for both MCI and $\mathrm{AD}$ subjects. The results suggest that at group level, cortical delta and alpha rhythms of MCI subjects were qualitatively affected by similar pathological mechanisms impinging upon the generation of cortical rhythms in mild $\mathrm{AD}$ subjects. In this sense, they are in favor of the hypothesis that most of the MCI subjects with ApoE genetic risk suffer from a preclinical stage of AD. However, this might not be true for all MCI subjects with ApoE genetic risk. Furthermore, the cognitive decline might not have the same progression in all these subjects. Therefore, these results motivate a follow-up study testing whether MCI subjects with ApoE genetic risk convert to mild $\mathrm{AD}$ as a function of the baseline alteration of cortical delta and alpha rhythms. 
We thank Dr L. Bartolo, Dr N. Flavio, Dr R. Basili, G. Busonero, M. Ercolani, R. Fini, Dr M. Gennarelli, Dr N. Girtler, Dr C. Bonato, Dr R. Manenti, Dr M. Gurzi, and Dr K. Sosta for their valuable help in the development of this study. We thank also Dr F. Eusebi for his continuous support.

\section{References}

1. Flicker CS, Ferris H, Reisberg B. Mild cognitive impairment in the elderly: predictors of dementia. Neurology 1991;41: 1006-1009.

2. Petersen RC, Smith GE, Ivnik RJ, et al. Apolipoprotein E status as a predictor of the development of Alzheimer's disease in memory-impaired individuals. JAMA 1995;273:1274-1278.

3. Petersen RC, Doody R, Kurz A, et al. Current concepts in mild cognitive impairment. Arch Neurol 2001;58:1985-1992.

4. Galluzzi S, Cimaschi L, Ferrucci L, Frisoni GB. Mild cognitive impairment: clinical features and review of screening instruments. Aging 2001;13:183-202.

5. Scheltens P, Fox N, Barkhof F, De Carli C. Structural magnetic resonance imaging in the practical assessment of dementia: beyond exclusion. Lancet Neurol 2002;1:13-21.

6. Arnaiz E, Almkvist O. Neuropsychological features of mild cognitive impairment and preclinical Alzheimer's disease. Acta Neurol Scand 2003;107:34-41.

7. Bachman DL, Wolf PA, Linn RT, et al. Incidence of dementia and probable Alzheimer's disease in a general population. The Framingham Study. Neurology 1993;43:515-519.

8. Gao S, Hendrie HC, Hall KS, et al. The relationships between age, sex, and the incidence of dementia and Alzheimer's disease. A meta-analysis. Arch Gen Psychiatry 1998;55:809-815.

9. Frisoni GB, Padovani A, Wahlund LO. The predementia diagnosis of Alzheimer disease. Alzheimer Dis Assoc Disord 2004; 18:51-53.

10. Petersen RC, Smith GE, Waring SC, et al. Mild cognitive impairment: clinical characterization and outcome. Arch Neurol 1999;56:303-308.

11. Braak H, Braak E. Neuropathological staging of Alzheimerrelated changes. Acta Neuropathol 1991;82:239-259.

12. Small GW, Rabins PV, Barry PP, et al. Diagnosis and treatment of Alzheimer disease and related disorders. Consensus statement of the American Association for Geriatric Psychiatry, the Alzheimer's Association, and the American Geriatrics Society. JAMA 1997;278:1363-1371.

13. Dierks T, Ihl R, Frolich L, Maurer K. Dementia of the Alzheimer type: effects on the spontaneous EEG described by dipole sources. Psychiatry Res 1993;50:51-162.

14. Dierks T, Jelic V, Pascual-Marqui RD, et al. Spatial pattern of cerebral glucose metabolism (PET) correlates with localization of intracerebral EEG-generators in Alzheimer's disease. Clin Neurophysiol 2000;111:1817-1824.

15. Huang C, Wahlund LO, Dierks T, et al. Discrimination of Alzheimer's disease and mild cognitive impairment by equivalent EEG sources: a cross-sectional and longitudinal study. Clin Neurophysiol 2000;11:1961-1967.

16. Ponomareva NV, Selesneva ND, Jarikov GA. EEG alterations in subjects at high familial risk for Alzheimer's disease. Neuropsychobiology 2003;48:152-159.

17. Babiloni C, Binetti G, Cassetta E, et al. Mapping distributed sources of cortical rhythms in mild Alzheimer's disease. A multi-centric EEG study. NeuroImage 2004;22:57-67.

18. Zappoli R, Versari A, Paganini M, et al. Brain electrical activity (quantitative EEG and bit-mapping neurocognitive $\mathrm{CNV}$ components), psychometrics and clinical findings in presenile subjects with initial mild cognitive decline or probable Alzheimer-type dementia. Ital J Neurol Sci 1995;16:341-376.
19. Jelic V, Shigeta M, Julin P. Quantitative electroencephalography power and coherence in Alzheimer's disease and mild cognitive impairment. Dementia 1996;7:314-323.

20. Grunwald M, Busse F, Hensel A, Kruggel F, et al. Links correlation between cortical theta activity and hippocampal volumes in health, mild cognitive impairment, and mild dementia. J Clin Neurophysiol 2001;18:178-184.

21. Grunwald M, Busse F, Hensel A, et al. Theta-power differences in patients with mild cognitive impairment under rest condition and during haptic tasks. Alzheimer Dis Assoc Disord 2002;16:40-48.

22. Frodl T, Hampel H, Juckel G, et al. Value of event-related P300 subcomponents in the clinical diagnosis of mild cognitive impairment and Alzheimer's disease. Psychophysiology 2002;39:175-181.

23. Elmstahl S, Rosen I. Postural hypotension and EEG variables predict cognitive decline: results from a 5-year follow-up of healthy elderly women. Dement Geriatr Cogn Disord 1997;8: $180-187$.

24. Jelic V, Johansson SE, Almkvist O, et al. Quantitative electroencephalography in mild cognitive impairment: longitudinal changes and possible prediction of Alzheimer's disease. Neurobiol Aging 2000;21:533-540.

25. Lahiri DK. Apolipoprotein E as a target for developing new therapeutics for Alzheimer's disease based on studies from protein, RNA, and regulatory region of the gene. J Mol Neurosci 2004;23:225-233.

26. Bunce D, Fratiglioni L, Small BJ, et al. APOE and cognitive decline in preclinical Alzheimer disease and non-demented aging. Neurology 2004;63:816-821.

27. Chou CY, Lin YL, Huang YC, et al. Structural variation in human apolipoprotein E3 and E4: secondary structure, tertiary structure, and size distribution. Biophys J 2004;88:455-466.

28. Corder EH, Saunders AM, Strittmatter WJ, et al. Gene dose of apolipoprotein E type 4 allele and the risk of Alzheimer's disease in late onset families. Science 1993;261:921-923.

29. Corder EH, Saunders AM, Pericak-Vance MA, Roses AD. There is a pathologic relationship between ApoE-epsilon 4 and Alzheimer's disease. Arch Neurol 1995;52:650-651.

30. Crutcher KA. Apolipoprotein E is a prime suspect, not just an accomplice, in Alzheimer's disease. J Mol Neurosci 2004;23: 81-88.

31. Huang Y, Weisgraber KH, Mucke L, Mahley RW. Apolipoprotein E: diversity of cellular origins, structural and biophysical properties, and effects in Alzheimer's disease. J Mol Neurosci 2004;23:189-204.

32. Lahiri DK, Sambamurti K, Bennett DA. Apolipoprotein gene and its interaction with the environmentally driven risk factors: molecular, genetic and epidemiological studies of Alzheimer's disease. Neurobiol Aging 2004;25:651-660.

33. Qiu C, Kivipelto M, Aguero-Torres H, et al.Risk and protective effects of the APOE gene towards Alzheimer's disease in the Kungsholmen project: variation by age and sex. J Neurol Neurosurg Psychiatry 2004;75:828-833.

34. Saunders AM, Strittmatter WJ, Schmechel D, et al. Association of apolipoprotein E allele E4 with late-onset alzheimer's disease. Neurology 1993;43:1467-1472.

35. Corder EH, Saunders AM, Risch NJ, et al. Protective effect of apolipoprotein E type 2 allele for late onset Alzheimer disease. Nat Genet 1994;7:180-184.

36. Rebeck GW, Kindy M, LaDu MJ. Apolipoprotein E and Alzheimer's disease: the protective effects of ApoE2 and E3. J Alzheimers Dis 2002;4:145-154.

37. Dal Forno G, Carson KA, Brookmeyer R, et al. APOE genotype and survival in men and women with Alzheimer's disease. Neurology 2002;58:1045-1050. 
38. Bartres-Faz D, Junque C, Lopez-Alomar A, et al. Neuropsychological and genetic differences between age-associated memory impairment and mild cognitive impairment entities. J Am Geriatr Soc 2001;49:985-990.

39. Feskens EJM, Havekes LM, Kalmijn S, et al. Apolipoprotein e4 allele and cognitive decline in elderly men. Br Med J 1994; 309:1202-1206.

40. Caselli RJ, Reiman EM, Osborne D, et al. Longitudinal changes in cognition and behavior in asymptomatic carriers of the APOE e4 allele. Neurology 2004;62:1990-1995.

41. Small GW, La Rue A, Komo S, et al. Predictors of cognitive change in middle-aged and older adults with memory loss. Am J Psychiatry 1995;152:1757-1764.

42. Reiman EM, Caselli RJ, Yun LS, et al. Preclinical evidence of Alzheimer's disease in persons homozygous for the e4-allele for apolipoprotein E. N Engl J Med 1996;334:752-758.

43. Bookheimer SY, Strojwas MH, Cohen MS, et al. Patterns of brain activation in people at risk for Alzheimer's disease. N Engl J Med 2000;343:450-456.

44. Lee KU, Lee JS, Kim KW, et al. Influence of the apolipoprotein $\mathrm{E}$ type 4 allele on cerebral glucose metabolism in Alzheimer's disease patients. J Neuropsychiatry Clin Neurosci 2003; $15: 78-83$.

45. Mosconi L, Nacmias B, Sorbi S, et al. Brain metabolic decreases related to the dose of the ApoE e4 allele in Alzheimer's disease. J Neurol Neurosurg Psychiatry 2004;75:370-376.

46. Scarmeas N, Anderson KE, Hilton J, et al.APOE-dependent PET patterns of brain activation in Alzheimer disease. Neurology 2004;63:913-915.

47. Small GW. Neuroimaging and genetic assessment for early diagnosis of Alzheimer's disease. J Clin Psychiatry 1996;57: $9-13$.

48. Small GW, Komo S, La Rue A, et al. Early detection of Alzheimer's disease by combining apolipoprotein $\mathrm{E}$ and neuroimaging. Ann NY Acad Sci 1996;802:70-78.

49. Jelic V, Julin P, Shigeta M, et al. Apolipoprotein E epsilon4 allele decreases functional connectivity in Alzheimer's disease as measured by EEG coherence. J Neurol Neurosurg Psychiatry 1997;63:59-65.

50. Lehtovirta M, Partanen J, Kononen M,. Spectral analysis in Alzheimer's disease: relation to apolipoprotein E polymorphism. Eur J Neurol 1995;2:129-d130.

51. Lehtovirta M, Partanen J, Kononen M, et al. Spectral analysis of EEG in Alzheimer's disease: relation to apolipoprotein E polymorphism. Neurobiol Aging 1996;17:523-526.

52. Lehtovirta M, Partanen J, Kononen M, et al. A longitudinal quantitative EEG study of Alzheimer's disease: relation to apolipoprotein E polymorphism. Dement Geriatr Cogn Disord 2000;11:29-35.

53. Babiloni C, Binetti G, Cassarino A, et al. Sources of cortical rhythms in adults during physiological aging: a multi-centric EEG study. Hum Brain Mapping 2005 [Epub ahead of print].

54. McKhann G, Drachman D, Folstein M, et al. Clinical diagnosis of Alzheimer's disease: report of the NINCDS-ADRDA Work Group under the auspices of Department of Health and Human Services Task Force on Alzheimer's disease. Neurology 1984;34:939-944.

55. Folstein MF, Folstein SE, McHugh PR. Mini Mental State: a practical method for grading the cognitive state of patients for clinician. J Psychiat Res 1975;12:189-198.

56. Hughes CP, Berg L, Danziger WL, et al. A new clinical rating scale for the staging of dementia. BrJ Psychiatry 1982;140: 1225-1230.

57. Yesavage JA, Brink TL, Rose TL, et al. Development and validation of a geriatric depression screening scale: a preliminary report. J Psychiatr Res 1982-83;17:37-49.
58. Rosen WG, Terry RD, Fuld PA, Katzman R, Peck A. Pathological verification of ischemic score in differentiation of dementias. Ann Neurol 1980;7:486-488.

59. Lawton MP, Brodie EM. Assessment of older people: self maintaining and instrumental activity of daily living. J Gerontol 1969;9:179-186.

60. Rubin EH, Morris JC, Grant EA, Vendegna T. Very mild senile dementia of the Alzheimer type. I. Clinical assessment. Arch Neurol 1989;46:379-382.

61. Albert M, Smith LA, Scherr PA, et al. Use of brief cognitive test to identify individuals in the community with clinically diagnosed Alzheimer's disease. Int J Neurosci 1991;57: $167-178$.

62. Zaudig M. A new systematic method of measurement and diagnosis of "mild cognitive impairment" and dementia according to ICD-10 and DSM-III-R criteria. Int Psychogeriatr 1992;4:203-219.

63. Devanand DP, Folz M, Gorlyn M, et al. Questionable dementia: clinical course and predictors of outcome. J Am Geriatr Soc 1997;45:321-328.

64. Petersen RC, Smith GE, Waring SC, et al. Aging, memory, and mild cognitive impairment. Int Psychogeriatr 1997;9: $65-69$.

65. Hixson JE, Vernier DT. Restriction isotyping of human apolipoprotein $\mathrm{E}$ by gene amplification and cleavage with HhaI. J Lipid Res 1990;31:545-548.

66. Buchan RJ, Nagata K, Yokoyama E, Langman, et al. Regional correlations between the EEG and oxygen metabolism in dementia of Alzheimer's type. Electroencephalogr Clin Neurophysiol 1997;103:409-417.

67. Muller TJ, Thome J, Chiaramonti R, et al. A comparison of qEEG and HMPAO-SPECT in relation to the clinical severity of Alzheimer's disease. Eur Arch Psychiatry Clin Neurosci 1997;247:259-263.

68. Pucci E, Belardinelli N, Cacchio G, et al .EEG power spectrum differences in early and late onset forms of Alzheimer's disease. Clin Neurophysiol 1999;110:621-631.

69. Szelies B, Mielke R, Kessler J, Heiss WD. EEG power changes are related to regional cerebral glucose metabolism in vascular dementia. Clin Neurophysiol 1999;110:615-620.

70. Rodriguez G, Vitali P, De Leo C, et al. Quantitative EEG changes in Alzheimer patients during long-term donepezil therapy. Neuropsychobiology 2002;46:49-56.

71. Babiloni C, Ferri R, Moretti DV, et al. Abnormal frontoparietal coupling of brain rhythms in mild Alzheimer's disease: a multicentric EEG study. Eur J Neurosci 2004;19: 2583-2590.

72. Moretti DV, Babiloni F, Carducci F, et al. Computerized processing of EEG-EOG-EMG artifacts for multicentirc studies in EEG oscillations and event-related potentials. Int J Pshycophysiol 2003;47:199-216.

73. Leuchter AF, Cook IA, Newton TF, et al. Regional differences in brain electrical activity in dementia: use of spectral power and spectral ratio measures. Electroenceph Clin Neurophysiol 1993;87:385-393.

74. Besthorn C, Zerfass R, Geiger-Kabisch C, et al. Discrimination of Alzheimer's disease and normal aging by EEG data. Electroencephalogr Clin Neurophysiol 1997;103:241-248.

75. Chiaramonti R, Muscas GC, Paganini M, et al. Correlations of topographical EEG features with clinical severity in mild and moderate dementia of Alzheimer type. Neuropsychobiology 1997;36:153-158.

76. Rodriguez G, Copello F, Nobili F, et al. EEG spectral profile to stage Alzheimer's disease. Clin Neurophysiol 1999;110: 1831-1837. 
77. Rodriguez G, Nobili F, Copello F, et al. 99mTc-HMPAO regional cerebral blood flow and quantitative electroencephalography in Alzheimer's disease: a correlative study. J Nucl Med 1999;40:522-529.

78. Cook IA, Leuchter AF. Synaptic dysfunction in Alzheimer's disease: clinical assessment using quantitative EEG.Behav Brain Res 1996;78:15-23.

79. Holschneider DP, Waite JJ, Leuchter AF, et al. Changes in electrocortical power and coherence in response to the selective cholinergic immunotoxin 192 IgG-saporin. Exp Brain Res 1999;126:270-280.

80. Klimesch W. Memory processes, brain oscillations and EEG synchronization. Int J Psychophysiol 1996;24:61-100.

81. Klimesch W. EEG alpha and theta oscillations reflect cognitive and memory performance: a review and analysis. Brain Res Rev 1999;29:169-195.

82. Nobili F, Taddei G, Vitali P, et al. Relationships between 99m Tc-HMPAO ceraspect and quantitative EEG observations in Alzheimer's disease. Arch Gerontol Geriatr 1998;6: 363-368.

83. Pucci E, Cacchiò G, Angeloni R, et al. EEG spectral analysis in Alzheimer's disease and different degenerative dementias. Arch Gereontol Geriatr 1997;26:283-297

84. Kolev V, Yordanova J, Basar-Eroglu C, Basar E. Age effects on visual EEG responses reveal distinct frontal alpha networks. Clin Neurophysiol 2002;113:901-910.

85. Klimesch W, Doppelmayr M, Pachinger T, Russegger $\mathrm{H}$. Event-related desynchronization in the alpha band and the processing of semantic information. Brain Res Cogn Brain Res 1997;6:83-94.

86. Klimesch W, Doppelmayr M, Russegger H, et al. Induced alpha band power changes in the human EEG and attention. Neurosci Lett 1998;244:73-76.

87. Babiloni C, Babiloni F, Carducci F, et al. Human alpha rhythms during visual delayed choice reaction time tasks. A MEG study. Hum Brain Mapping 2004;24:184-192.

88. Babiloni C, Babiloni F, Carducci F, et al. Human cortical rhythms during visual delayed choice reaction time tasks. A high-resolution EEG study on normal aging. Behav Brain Res 2004;153:261-271.

89. Babiloni C, Miniussi C, Babiloni F, et al. Sub-second "temporal attention" modulates alpha rhythms. A high-resolution EEG study. Cogn Brain Res 2004;19:259-268.

90. Babiloni C, Babiloni F, Carducci F, et al. Human cortical responses during one-bit short-term memory: a high-resolution EEG study on delayed choice reaction time tasks. Clin Neurophysiol 2004;115:161-170.

91. Babiloni C, Babiloni F, Carducci F, et al. Human cortical EEG rhythms during long-term episodic memory task: a high resolution EEG study of the HERA model. Neuroimage 2004; 21:1576-1584.

92. Pascual-Marqui RD, Michel CM, Lehmann D. Low resolution electromagnetic tomography: a new method for localizing electrical activity in the brain. Int J Psychophysiol 1994;18: 49-65.

93. Pascual-Marqui RD, Lehmann D, Koenig T, et al. Low resolution brain electromagnetic tomography (LORETA) functional imaging in acute, neuroleptic-naive, first-episode, productive schizophrenia. Psychiatry Res 1999;90:169-179.

94. Pascual-Marqui RD, Esslen M, Kochi K, Lehmann D. Functional imaging with low resolution brain electromagnetic tomography (LORETA): a review. Methods Find Exp Clin Pharmacol 2002;24:91-95.

95. Yao D, He B. A self-coherence enhancement algorithm and its application to enhancing three-dimensional source estimation from EEGs. Ann Biomed Eng 1997;29:1019-1027.
96. Phillips C, Rugg MD, Friston KJ. Systemic regularization of linear inverse solutions of the EEG source localization problem. Neuroimage 2002;17:287-301.

97. Mulert C, Pogarell O, Juckel G, et al. The neural basis of the P300 potential. Focus on the time-course of the underlying cortical generators. Eur Arch Psychiatry Clin Neurosci 2004; 254:190-198.

98. Oakes TR, Pizzagalli DA, Hendrick AM, et al. Functional coupling of simultaneous electrical and metabolic activity in the human brain. Hum Brain Mapp 2004;21:257-270.

99. Mulert C, Jager L, Schmitt R, et al. Integration of fMRI and simultaneous EEG: towards a comprehensive understanding of localization and time-course of brain activity in target detection. Neuroimage 2004;22:83-94.

100. Mulert C, Jager L, Propp S, et al. Sound level dependence of the primary auditory cortex: simultaneous measurement with 61-channel EEG and fMRI. Neuroimage 2005;28:49-58.

101. Talairach J, Tournoux P. Co-planar stereotaxic atlas of the human brain. Stuttgart: Thieme, 1988.

102. Anderer P, Saletu B, Pascual-Marqui RD. Effect of the 5-HT(1A) partial agonist buspirone on regional brain electrical activity in man: a functional neuroimaging study using low-resolution electromagnetic tomography (LORETA). Psychiatry Res 2000;100:81-96.

103. Anderer P, Saletu B, Semlitsch HV, Pascual-Marqui RD. Non-invasive localization of P300 sources in normal aging and age-associated memory impairment. Neurobiol Aging 2003; 24:463-479.

104. Anderer P, Saletu B, Saletu-Zyhlarz G, et al. Brain regions activated during an auditory discrimination task in insomniac postmenopausal patients before and after hormone replacement therapy: low-resolution brain electromagnetic tomography applied to event-related potentials. Neuropsychobiology 2004;49:134-153.

105. Isotani $\mathrm{T}$, Lehmann $\mathrm{D}$, Pascual-Marqui $\mathrm{RD}$, et al. EEG source localization and global dimensional complexity in highand low-hypnotizable subjects: a pilot study. Neuropsychobiology 2001;44:192-198.

106. Kawasaki T, Tanaka S, Wang J, et al. Abnormalities of P300 cortical current density in unmedicated depressed patients revealed by LORETA analysis of event-related potentials. Psychiatry Clin Neurosci 2004;58:68-75.

107. Mulert C, Gallinat J, Pascual-Marqui R, et al. Reduced eventrelated current density in the anterior cingulate cortex in schizophrenia. Neuroimage 2001;13:589-600.

108. Winterer G, Mulert C, Mientus S, et al. P300 and LORETA: comparison of normal subjects and schizophrenic patients. Brain Topogr 2001;13:299-313

109. Laufer I, Pratt H. Evoked potentials to auditory movement sensation in duplex perception. Clin Neurophysiol 2003;114: 1316-1331.

110. Laufer I, Pratt H. The electrophysiological net response ("Fcomplex") to spatial fusion of speech elements forming an auditory object. Clin Neurophysiol 2003;114:818-834.

111. Cincotti F, Babiloni C, Miniussi C, et al. EEG deblurring techniques in a clinical context. Methods. Inf Med 2004;43: 114-117

112. Veiga H, Deslandes A, Cagy M, et al. Neurocortical electrical activity tomography in chronic schizophrenics. Arq Neuropsiquiatr 2003;61:712-717.

113. Nuwer MR. Quantitative EEG. I: techniques and problems of frequency analysis and topographic mapping. J Clin Neurophysiol 1988;5:1-43.

114. Hernández JL, Valdés P, Biscay R, et al. A global scale factor in brain topography. Int J Neurosci 1994;76:267-278. 
115. Cook DG, Leverenz JB, McMillan PJ, et al. Reduced hippocampal insulin-degrading enzyme in late-onset Alzheimer's disease is associated with the apolipoprotein E-epsilon4 allele. Am J Pathol 2003;162:313-319.

116. Kar S, Slowikowski SP, Westaway D, Mount HT. Interactions between beta-amyloid and central cholinergic neurons: implications for Alzheimer's disease. J Psychiatry Neurosci 2004;29: 427-441.

117. Steriade M, Llinas RR. The functional states of the thalamus and the associated neuronal interplay. Physiol Rev 1988;68: 649-742.

118. Brunia $\mathrm{CH}$. Neural aspects of anticipatory behavior. Acta Psychol (Amst) 1999;101:213-242.

119. Pfurtscheller G, Lopez da Silva F. Event-related EEG/MEG synchronization and desynchronization: basic principles. Clin Neurophysiol 1999;110:1842-1857.

120. Buser P. Thalamocortical mechanisms underlying synchronised EEG activity. A textbook of clinical neurophysiology: (Halliday AM, Butler SR, Paul R, eds), pp 595-621. Chichester, UK: Wiley, 1987.

121. Rossini PM, Desiato MT, Lavaroni F, Caramia MD. Brain excitability and electroencephalographic activation: noninvasive evaluation in healthy humans via transcranial magnetic stimulation. Brain Res 1991;567:111-119.

122. Ricceri L, Minghetti L, Moles A, et al. Cognitive and neurological deficits induced by early and prolonged basal forebrain cholinergic hypofunction in rats. Exp Neurol 2004;189: 162-172

123. Sarter M, Bruno JP. Cognitive functions of cortical acetylcholine: toward a unifying hypothesis. Brain Res Brain Res Rev 1997;23:28-46.

124. Sarter M, Bruno JP. Age-related changes in rodent cortical acetylcholine and cognition: main effects of age versus age as an intervening variable. Brain Res Brain Res Rev 1998;27: 143-156.

125. Kobayashi Y, Tadashi I. Sensory-motor gating and cognitive control by the brainstem cholinergic system. Neural Networks 2002:731-741.

126. Muzur A, Pace-Schott EF, Hobson JA. The prefrontal cortex in sleep. Trends Cogn Sci 2002;6:475-481.
127. Babiloni C, Babiloni F, Carducci F, et al. Movement-related electroencephalographic reactivity in Alzheimer disease. Neuroimage 2000;12:139-146.

128. Babiloni C, Cassetta E, Chiovenda P, et al. Frontomedial alpha hyper-reactivity in mild demented patients during visual delayed response tasks. A MEG study. Brain Res Bull 2005; 65:457-470.

129. Alagona G, Bella R, Ferri R, et al. Transcranial magnetic stimulation in Alzheimer disease: motor cortex excitability and cognitive severity. Neurosci Lett 2001;314:57-60.

130. Ferri R, Del Gracco S, Elia M, et al. Scalp topographic mapping of middle-latency somatosensory evoked potentials in normal aging and dementia. Neurophysiol Clin 1996;26: 311-319.

131. Ferreri F, Pauri F, Pasqualetti P, et al. Motor cortex excitability in Alzheimer's disease: a transcranial magnetic stimulation study. Ann Neurol 2003;53:102-108.

132. Pennisi G, Alagona G, Ferri R, et al. Motor cortex excitability in Alzheimer disease: one year follow-up study. Neurosci Lett 2002;329:293-296.

133. Holschneider DP, Leuchter AF, Scremin OU, et al. Effects of cholinergic deafferentation and NGF on brain electrical coherence. Brain Res Bull 1998;45:531-541.

134. Mesulam M. The cholinergic lesion of Alzheimer's disease: pivotal factor or side show? Learning Memory 2004: 1143-1149.

135. Mesulam M, Shaw P, Mash D, Weintraub S. Cholinergic nucleus basalis tauopathy emerges early in the aging-MCI-AD continuum. Ann Neurol 2004;55:815-828.

136. Mash DC, Flynn DD, Potter LT. Loss of M2 muscarine receptors in the cerebral cortex in Alzheimer's disease and experimental cholinergic denervation. Science 1985;228: 1115-1117.

137. Geula C, Mesulam MM. Cortical cholinerigc fibers in aging and Alzheimer's disease: a morphometirc study. Neuroscience 1989;33:469-481.

138. Geula C, Mesulam MM. Systematic regional variations in the loss of cortical cholinergic fibers in Alzheimer's disease. Cereb Cortex 1996;6:165-177.

139. Geula C, Mesulam MM. Cholinergic system in Alzheimer's disease. 2nd ed. In: Alzheimer disease, Terry RD, et al., eds. Philadelphia: Lippincott, 1999. 